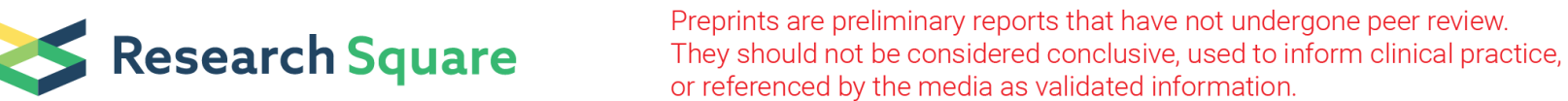

\section{Model Error-Induced Biases of Greenhouse Gas Contribution to Global Warming: A Piecewise Integration Approach}

\section{Yumei Li}

Sun Yat-Sen University

Fei Liu

Sun Yat-Sen University

\section{Xuejiao Wang}

Tianjin Meteorological Center

Wenjie Dong ( $\nabla$ dongwj3@mail.sysu.edu.cn )

Sun Yat-Sen University

\section{Tanlong Dai}

National Climate Center

\section{Research Article}

Keywords: model biases, piecewise integration, global warming attribution, greenhouse gases

Posted Date: May 27th, 2021

DOl: https://doi.org/10.21203/rs.3.rs-524584/v1

License: (c) (1) This work is licensed under a Creative Commons Attribution 4.0 International License. Read Full License

Version of Record: A version of this preprint was published at Climate Dynamics on January 23rd, 2022. See the published version at https://doi.org/10.1007/s00382-021-06089-w. 


\section{Abstract}

Many of the observed changes of the climate system since the 1950s are unprecedented, and there is a high level of confidence in the conclusion that greenhouse gases (GHGs) caused a substantial part of the observed global warming. We need to consider the model errors, that usually accumulate in long-term integration as a result of imperfect physical and numerical representations, to attribute climate changes using model simulations. Here, we present a new method of the piecewise integration (PWI) with simulation corrected by the observation at each step, to identify model error-induced bias of global warming in the Community Earth System Model (CESM). To confirm the hypothesis of constant modelobservation bias under different external forcing, we disturb the original CESM into a less low-cloud version and take its historical and GHGs-fixed simulations as our "observations". In the PWI historical and GHGs-fixed runs of original CESM from 1958 to 2005, we use the difference between "historical observation" and PWI historical run to correct both PWI runs at the end of each 1-day step. The results show that the PWI can effectively reduce model's cumulative error and presents a GHGs-induced global warming trend of $0.688^{\circ} \mathrm{C}(48 \mathrm{yr})^{-1}$, which is very close to the "observational" trend of $0.683^{\circ} \mathrm{C}(48 \mathrm{yr})^{-1}$, confirming the hypothesis of constant model bias under different external forcing. The continuous runs, as usually done by the Coupled Model Intercomparison Project (CMIP) models, present a much higher GHGs-induced global warming trend of $0.887^{\circ} \mathrm{C}(48 \mathrm{yr})^{-1}$, which means that the model overestimates the GHGs's role in global warming trend by $32.3 \%$ compared to our "observations". Global distribution of this model bias is also discussed. The PWI method provides a new way to correct model biases in analyzing relative contribution of anthropogenic and natural forcing to global warming.

\section{Introduction}

The successive reports of the Intergovernmental Panel on Climate Change (IPCC) have offered increasingly confident assessments of the dominant role of anthropogenic factors in causing current global warming (Parry et al. 2007). Despite the high level of confidence in the conclusion that greenhouse gases (GHG) caused a substantial part of the observed warming, however, there remain many uncertainties that have so far limited the potential to be more precise about attribution statements (Jones et al. 2013). These uncertainties include both observational uncertainty caused by measurement biases in datasets and uneven distribution of meteorological observation stations in the globe (Cowtan and Way 2014; Frei and Isotta 2019; Matthew et al. 2017), and simulation uncertainty of numerical models. The uncertainty of simulations is mainly due to the incomplete representation of the climate system and its dynamical and physical configurations in numerical models(Jones et al. 2013; Morice et al. 2012). To reduce observational errors, data assimilation methods are often used to effectively absorb the observation information of different levels and spatial distribution; based on this, the quality of initial fields can be improved, and the errors caused by the lack of observations in high-latitude polar regions and vast ocean areas can be reduced to some extent, which can improve the quality of model simulations and reduce the growth of internal errors (Kalnay 2002). Moreover, improving physical module of the model is an important way to reduce simulation errors in the numerical model. Although current climate 
models have been greatly improved after decades of efforts, there still exist many shortcomings in describing some physical processes and the coupled ocean-atmosphere and land-atmosphere processes (Bony et al. 2015; Cesana and Waliser 2016; Gupta et al. 2013; Koster et al. 2014; Nam et al. 2012; Stevens and Bony 2013).

Improving the performance of the numerical model is an arduous and long-term task. Many researchers have improved simulation methods to reduce the uncertainty of simulation based on the existing models. For example, the data assimilation method is used to introduce the observation as a constraint, which can improve the accuracy of the initial field (Kalnay 2002; Lorenc 2015; Sagita and Fatkhuroyan 2016; Wang et al. 2020; Wu et al. 2020). The multi-model ensembles or perturbed parameter ensembles can eliminate the random error to a certain extent (Chai et al. 2020; Cornes et al. 2018; Hawkins and Sutton 2009; Kennedy et al. 2019; Knutti et al. 2010; Tebaldi and Knutti 2007); however, such approach needs enough ensemble members and cannot eliminate possible systematic error. A series of studies have shown that the re-initialization method can eliminate the drift and bias of the simulated state; the results obtained by multiple short-term integrals are closer to the observational data than those from continuous runs (Bennett and Leslie 1981; Ji and Vernekar 2010; Lo et al. 2008; Lucas-Picher et al. 2013; Pan et al. 1999; Qian et al. 2003b). However, re-initialization method is not used for the historical run and sensitivity runs with different external forcings in the Coupled Model Intercomparison Project (CMIP) models.

Similar to the re-initialization in the dynamic downscaling (Bennett and Leslie, 1981), the piecewise integration (PWI) approach was proposed for sensitivity experiment to mitigate accumulation systematic errors in the traditional continuous (CONT) long-term simulations (Zhang et al. 2008). The PWI splits the continuous long-term simulation into subintervals of sequential short-term simulations. The initial fields of the numerical model including the historical run and sensitivity run with certain external forcing fixed are updated by re-initialization at the beginning of each subinterval, and the states of the simulation of historical run are constantly re-initialized with the observations or reanalysis data, while the states of sensitivity run are constantly updated by adding the difference between the state of historical run and reanalysis data. In this way, the drifts of the climate model can be effectively corrected, which will improve simulation accuracy of the climate model. This approach was validated with a simple sixparameter model, and the results indicated that it is able to reduce the error accumulation caused by longtime continuous integration and improve the credibility of numerical simulation (Zhang et al. 2008). A more comprehensive assessment of the applicability of the PWI was conducted under broader scenarios through experiments with the shallow-water model (Shao et al. 2015), and the influences of analysis data error and subinterval length on the results were investigated (Shao et al. 2015). A series of idealized sensitivity experiments were carried out to study the contribution of GHGs emissions to climate change in the past 26 years of 1979-2004 by the Community Earth System Model (CESM), and the experiments showed that the PWI can effectively reduce the systematic error; however, the simulated time is not long enough to identify the global warming trend (Wang 2017), thus it is important to further analyze the performance of the PWI by using long-term ensembles. 
In this study, we conducted a series of idealized experiments to investigate the influence of external GHGs forcing change on the climate with the CESM, which include the historical simulations and GHGs-fixed simulations. In addition, a more comprehensive assessment of the applicability of the PWI was assessed by the comparison of perturbed initial conditions ensembles of the CONT.

\section{Method And Numerical Model}

\subsection{The PWI approach}

To evaluate the contribution of the external forcing to past climate change, the climate model can be run with changing external forcing and constant external forcing. The first simulation was performed with actual forcing including realistic changing of anthropogenic and natural forcing, which can be called historical simulation. The other simulation was performed with external forcing fixed, for example, the GHGs concentration was fixed at its initial value and kept constant throughout the run. We called this case a GHG-fixed simulation. The averaged difference over a long period is then defined as the effects of the GHGs on climate change; and it is also one of the most concerned quantity in the study of climate attribution. Conventionally, both the states of historical simulation and GHGs-fixed simulation in the sensitivity experiments are obtained through the continuous long-term model integrations, as done in CMIPs. However, the model errors may accumulate in long-term continuous integration as a result of incomplete physical and numerical representation (Andreao et al. 2019; Qian et al. 2003).

To improve the accuracy of the simulation, the state of historical simulation can be constrained with the observations or reanalysis data through nudging or re-initialization. The PWI splits the entire integration period into subintervals of sequential short-term simulations, and the state of historical simulation of the model is updated by observations or reanalysis data at the end of each subinterval. Due to the lack of observations or reanalysis data as constraints, the state of GHGs-fixed simulation is also updated by superimposing the difference between re-initialization and the historical simulation state at the end of each subinterval, based on the hypothesis of constant model error under different external forcing.

The PWI has been proved to be effective in reducing the simulation errors (Gan et al. 2019; Shao et al. 2015; Zhang et al. 2008). In the following section, a complex climate model is used to test the simulations of GHGs-induced global climate change using both the CONT and the PWI.

\subsection{Model description}

The CESM version 1.2.0 (Hurrell et al. 2013) is a fully coupled Earth System Model, which was developed from the Community Climate System Model, version 4 (CCSM4). It is composed of seven geophysical model components, including atmosphere, land, ocean, land ice, runoff, sea ice, and waves, and a central coupler that passes information among them. The components can be configured according to different simulation purposes and requirements (Hurrell et al. 2013). The component set is defined as B20TRC5 in the CESM1.2.0 is used in the sensitivity experiments for this study. This component set is coupled the earth's atmosphere (CAM5.0), ocean (POP2.0), land surface (CLM4.0), land ice (CISM), runoff (RTM), sea 
ice (CICE4.0), and it includes the central coupler (CPL7). The atmospheric component is the Community Atmosphere Model, version 5 (CAM5), which uses the Lin-Rood finite-volume dynamic core with the horizontal resolution of $1.9^{\circ} \times 2.5^{\circ}$, and 30 levels in the vertical direction arranged in a hybrid pressure sigma coordinate system (Neale et al. 2010). The ocean component has the horizontal resolution of g16, corresponding to a nominal grid size of $1^{\circ} \times 1^{\circ}$; there are 60 isopycnic layers in the vertical. The horizontal resolution of the land-surface and land-ice models are $1.9^{\circ} \times 2.5^{\circ}$, and the sea-ice model has the horizontal resolution is $1^{\circ} \times 1^{\circ}$. More detailed description of the CESM1.2.0 can be found at the website: https://www.cesm.ucar.edu/models/cesm1.2.

\subsection{Experimental designs}

To evaluate the advantages of the PWI compared to the CONT, a series of idealized sensitivity experiments were carried out with the model data, before using the observational data or reanalysis data for numerical simulations in the future works. Two different CESM versions denoted by CESM1.2.0 and CESM1.2.0_rl_0.9 were used. The CESM1.2.0_rl_0.9 is regarded as the "perfect model" without errors, and the simulation results are regarded as "observation" to test the accuracy of the other simulations and provide analysis fields for the PWI. The CESM1.2.0 represents a model with systematic errors, which is used for sensitivity experiments with the PWI and CONT (Fig. 1). The only difference between the two versions is that the minimum threshold for low stable clouds (denoted as $\mathrm{rl}$ ): the $\mathrm{rl}$ in CESM1.2.0 is 0.8875, which is the default value of CESM1.2.0, while the rl value in CESM1.2.0_rl_0.9 is 0.9, resulting in less low clouds in CESM1.2.0_rl_0.9 than in CESM1.2.0.

To make it easier to distinguish the impact of GHGs emissions on climate change from that of the other forcing, we conduct two groups of simulation for climate sensitivity experiments as shown in Fig. 1. The first group of simulations were performed with "actual forcing" including anthropogenic and natural forcing, which are historical simulations (called FULL simulations). The other group of simulations were performed with fixed GHGs concentration throughout the integration, which have the same concentration as that in 1958 (called GHGs-fixed simulations). The GHGs in the simulations include $\mathrm{CO}_{2}, \mathrm{~N}_{2} \mathrm{O}, \mathrm{CH}_{4}$, $\mathrm{CFC}_{11}$, and $\mathrm{CFC}_{12}$. The difference between the two groups could be regarded as the contribution of $\mathrm{GHGs}$ to climate change. The "observational" historical and GHG-fixed runs were performed by using CESM1.2.0_rl_0.9 through CONT integration from 1958 to 2005. The PWI historical and GHG-fixed runs were performed by using CESM1.2.0, which are both corrected by the same difference between the PWI and "observational" historical runs, based on the hypothesis of constant model error under different external forcing (Fig. 1).

To comprehensively evaluate the reliability of the PWI, ensemble experiments of the CONT were also run with six ensemble members by using CESM1.2.0. The initial fields were unperturbed in the first ensemble experiment, while in each of the remaining five ensemble members, a small random disturbance was generated from the range $(-0.01 \mathrm{~K}, 0.01 \mathrm{~K})$ to the initial air temperature field. It is worth pointing out that the temperature and wind fields of the PWI were updated after every 24 hours in all the numerical 
simulations, and the small initial disturbance has relatively small effects on the simulation results, so the PWI has only one ensemble. All these experiments are summarized in Table 1.

Table 1

List of the numerical simulations

\begin{tabular}{|llll|}
\hline Named experiment & Method & Model & Updated variables \\
\hline “observation”_Historical & CONT & CESM1.2.0_rl_0.9 & NaN \\
\hline “observation”_GHG-fixed & CONT & CESM1.2.0_rl_0.9 & NaN \\
\hline PWI_Historical & PWI & CESM1.2.0 & T, U, V \\
\hline PWI_GHG-fixed & PWI & CESM1.2.0 & T, U, V \\
\hline CONT_Historical (Six members) & CONT & CESM1.2.0 & NaN \\
\hline CONT_GHG-fixed (Six members) & CONT & CESM1.2.0 & NaN \\
\hline
\end{tabular}

\section{Results}

To identify the model bias of GHG contribution to global warming, this section is organized in three parts. We first show the advantage of the PWI is over the CONT by comparing the average 2-m temperature difference variation with latitude between the PWI simulation and the "observation", and that of between the CONT simulation and the "observation". We then present the temporal variations of global 2-m temperature and precipitation in the "observations", the CONT and the PWI simulations. Finally, we exhibit the spatial distributions of 2-m temperature trends and precipitation trends in the PWI and the CONT simulation, by compared to the "observation".

\subsection{Updated climatology by PWI}

Figure 2a shows the latitude distribution of average 2-m temperature difference in the historical simulation between the PWI and the "observation", and that between the CONT and the "observation". The globally averaged 2-m temperature variation with latitude in the CONT simulation is smaller than that of the "observation", and the uncertainty of the simulation in the mid-to-high latitudes of the Northern Hemisphere is larger than in tropics. The maximum bias of CONT ensemble mean reaches $-1.527^{\circ} \mathrm{C}$ at $90^{\circ} \mathrm{N}$, while the maximum bias of the PWI simulation is only $0.025^{\circ} \mathrm{C}$ ). The $2-\mathrm{m}$ temperature simulated by the PWI is closer to the "observation", and can better reproduce the "observational" change with altitude.

Figure $2 \mathrm{~b}$ shows the GHGs-fixed simulation. Similar to historical simulation (Fig. 2a), the average 2-m temperature variation with latitude in the CONT simulation is also smaller than that of the "observation", and the uncertainty of simulation in the mid-to-high latitudes of the Northern Hemisphere is large. The maximum bias of CONT ensemble mean reaches $-0.876^{\circ} \mathrm{C}$ at $90^{\circ} \mathrm{N}$, while the maximum bias of the PWI 
is $0.32^{\circ} \mathrm{C}$ at $64^{\circ} \mathrm{S}$. The temperature simulated by the PWI is closer to the "observation", and can better describe the change with the latitude.

Figure 2c exhibits the effected of GHGs, represented by the difference between historical and GHG-fixed runs. The uncertainty of simulation by the CONT in the mid-to-high latitudes of the Northern Hemisphere is larger than in tropics, and the maximum bias of CONT ensemble mean reaches $-0.651^{\circ} \mathrm{C}$ at $90^{\circ} \mathrm{N}$, while the maximum bias of PWI simulation is $0.316^{\circ} \mathrm{C}$ at about $64^{\circ} \mathrm{S}$. The errors in the state of the historical simulation and that of the GHGs-fixed simulation simulated by the CONT are partially offset, which result in the bias of GHGs contribution to climate change being smaller, but the bias of the CONT simulation is still higher than that of the PWI simulation. These results mean that the PWI can remove the model-observation bias very well.

\subsection{Temporal variations of global temperature and precipitation}

Temporal variation of global annual 2-m temperature is provided in Fig. 3a. The globally averaged 2-m temperatures in the simulations of the PWI, the CONT ensemble mean, and the "observation" all have significant increasing trends. The globally averaged error of the PWI relative to the "observation" is significantly smaller than that of the CONT ensemble mean; the former can well reproduce the trend of the globally averaged 2-m temperature of the "observation." The globally averaged 2-m temperature trends of the "observation", the PWI, and the CONT ensemble mean are $0.773^{\circ} \mathrm{C}$ (48 year) $-1,0.771^{\circ} \mathrm{C}$ (48 year) -1 , and $0.523^{\circ} \mathrm{C}$ (48 year) -1 , respectively. It is obvious that the accuracy of PWI simulation is much higher than that of CONT ensemble mean. The globally averaged 2-m temperature simulated by the PWI and the CONT are lower than the "observation". The reason is that the relative humidity threshold of the low cloud in CESM1.2.0 used for sensitivity experiments with the PWI and the CONT is lower than that in the CESM1.2.0_rl_0.9 for "observations"; thus, there are more low clouds formed and less incoming shortwave radiation in the CESM1.2.0 than in CESM1.2.0_rl_0.9.

Figure 3b shows the simulation of GHGs emissions fixed at the level in 1958. It is obvious from the figure that the temporal variation of globally averaged 2-m temperature of the simulation by the PWI is closer to "observation", and the globally averaged 2-m temperature trends of the "observation", the PWI, and the CONT ensemble mean are $0.090^{\circ} \mathrm{C}(48 \text { year })^{-1}, 0.083^{\circ} \mathrm{C}(48 \text { year })^{-1}$, and $-0.364^{\circ} \mathrm{C}(48 \text { year })^{-1}$, respectively. Thus, the error of the PWI relative to the "observation" is significantly smaller than that of CONT ensemble mean, which confirms that hypothesis of constant model-observation bias under different external forcing. Compared to the historical run, the PWI GHG-fixed simulation is not that good as in historical run, since the state of the PWI GHGs-fixed simulation is updated by adding the difference between "observational" and PWI historical runs.

Figure 3c shows the GHGs contribution to current global warming, which can be represented by the difference between the state of historical simulation and that of GHGs-fixed simulation during 19582005. The result of the PWI presents a GHGs-induced global warming trend of $0.688^{\circ} \mathrm{C}(48 \text { year })^{-1}$, which 
is very close to the "observation" of $0.683^{\circ} \mathrm{C}(48 \text { year })^{-1}$, while the result of CONT ensemble mean presents a much higher GHGs-induced global warming trend of $0.887^{\circ} \mathrm{C}(48 \text { year })^{-1}$, which means that the model overestimates the GHGs role in global warming trend by $32.3 \%$ compared to the "observation." Therefore, the simulation accuracy and reliability of the PWI are higher than those of the CONT, which is usually used in our current CMIPs.

Temporal variation of global annual precipitation is provided in Fig. 4a. The globally averaged error of the PWI relative to the "observation" is significantly smaller than that of CONT ensemble mean, and the PWI can better reproduce the trend of global annual precipitation of the "observation" than the CONT. The globally averaged precipitation trends of the "observation", the PWI, and the CONT ensemble mean are $0.017 \mathrm{~mm} \mathrm{day}^{-1}$ (48 year) ${ }^{-1}, 0.013 \mathrm{~mm} \mathrm{day}^{-1}$ (48 year) $)^{-1}$, and $-0.02 \mathrm{~mm} \mathrm{day}^{-1}$ (48 year) ${ }^{-1}$, respectively. It is obvious that the accuracy of the PWI simulation is higher than that of the CONT ensemble mean. The trend of global precipitation simulated by the PWI and the CONT ensemble mean are lower than the "observation". The simulation of precipitation by the PWI is not as good as that of 2-m temperature, and the reason may be due to the fact that the specific humidity has not been updated, which should be considered in the future work.

Figure $4 \mathrm{~b}$ shows the precipitation change in the GHG-fixed simulations. The temporal variation of globally averaged precipitation trend of the PWI simulation is slightly closer to the "observation" than that of CONT ensemble mean; and the globally averaged precipitation trends of the "observation," PWI, and CONT ensemble mean in the GHGs-fixed simulation are $0.003 \mathrm{~mm}$ day $^{-1}$ (48 year) ${ }^{-1},-0.008 \mathrm{~mm}$ day $^{-1}$

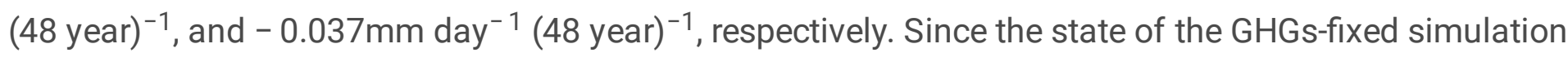
by the PWI is updated by superimposing the difference between "observation" and the historical simulation at the end of each subinterval, and the specific humidity closely related to precipitation is also not updated, the high accuracy of PWI simulation cannot be guaranteed. However, the error of the PWI simulation is still much smaller than that of the CONT ensemble mean.

Figure 4c shows the GHGs contribution to the global precipitation change, which is represented the difference by the historical simulation and GHGs-fixed simulation. The global precipitation trends of the "observation," PWI, and CONT ensemble mean are $0.013 \mathrm{~mm} \mathrm{day}^{-1}$ (48 year) ${ }^{-1}, 0.020 \mathrm{~mm}^{-1 a y}{ }^{-1}$ (48 year) ${ }^{-1}$, and $0.035 \mathrm{~mm}$ day $^{-1}$ (48 year) ${ }^{-1}$, respectively. Which means that the PWI overestimates the GHGs role in global precipitation trend by $53.8 \%$ compared to the "observation." While the CONT ensemble mean overestimates the GHGs role in global precipitation trend by $169.2 \%$ compared to the "observation". The trend of globally averaged precipitation caused by GHGs in PWI simulation is closer to the "observation" than that of the CONT ensemble mean.

Compared to temperature, the trend of precipitation change is much weaker due to more stable troposphere under the anthropogenic GHG forcing-induced global warming (Held and Soden 2006). This may be one reason that the PWI method didn't perform well in diagnosing the small precipitation trend. Implement of the moisture in PWI may also improve our PWI method isolating the model bias. 


\subsection{Spatial distributions of 2-m temperature and precipitation trends}

Figure 5 shows maps of 48-yr (1958-2005) GHGs-induced 2-m temperature trend from the six members of the CONT ensemble, as well as those from the "observation", the PWI simulation and the CONT ensemble mean. The 2-m temperature trend varies obviously across individual ensemble members, despite the fact that each simulation was conducted using the same model and subjected to the identical radiative forcing. Although it is evident that ensemble members show warming in most regions of the world, consistent with our expectation because of anthropogenic GHGs emissions, it is clear that there are large warming differences among different ensemble members in the mid and high latitudes of the Northern Hemisphere.

The "observation" trend of GHGs-induced 2-m temperature (Fig. 5, bottom-right panel) is positive in most regions, with the largest warming caused by GHGs $\left(>1.6^{\circ} \mathrm{C}\right.$ over 48 year) over Greenland, northeastern Canada and its nearby waters. While the largest cooling caused by $\mathrm{GHGs}\left(<-0.8^{\circ} \mathrm{C}\right.$ over 48 year) in the Southeast Pacific, the Atlantic Ocean near North America $\left(40^{\circ}-60^{\circ} \mathrm{N}\right)$ and Russia. However, none of the CONT ensemble members' simulation, including the ensemble mean, is consistent with the "observation" in these cooling areas, while the PWI can simulate some cooling areas, say the Pacific Ocean near South America as in the "observation". Moreover, Fig. 6 shows that the difference of GHGs-induced 2-m temperature trend between the PWI simulation and the "observation" is smaller than that between the CONT simulation and the "observation". The difference of 2-m temperature trend between the simulation of each member of the CONT ensemble and the "observation" range from $0.08^{\circ} \mathrm{C}$ to $0.407^{\circ} \mathrm{C}$ (48 year) $)^{-1}$, and that between the CONT ensemble mean and the "observation" is $0.204^{\circ} \mathrm{C}$ (48 year) ${ }^{-1}$. While the difference of 2-m temperature trend between the PWI simulation and the "observation" is only $0.006^{\circ} \mathrm{C}$ $(48 \text { year })^{-1}$. Each member of the CONT ensemble, as well as the CONT ensemble mean and the PWI simulation, are quite different from the "observation" in high latitudes of the Northern Hemisphere.

The degree of resemblance between the "observation" and simulated trend maps can be quantified in terms of centered pattern correlation (e.g., the area-averaged 2-m temperature trend is removed before computing the pattern correlation) and root-mean-square error (RMSE). Pattern correlations between each member of the CONT ensemble and the "observation" range from 0.192 to 0.360 , and RMSE range from $0.429^{\circ} \mathrm{C}$ to $1.087^{\circ} \mathrm{C}$ (48 year) ${ }^{-1}$. Pattern correlation between the CONT ensemble mean and the "observation" is 0.356 , and RMSE is $0.410^{\circ} \mathrm{C}$ (48 year $)^{-1}$. While the pattern correlation of the PWI and "observation" is 0.533 , and the RMSE is $0.299^{\circ} \mathrm{C}$ (48 year) $)^{-1}$ (Fig. 5). The results show that the ensemblemean of the CONT simulation still cannot eliminate possible systematic errors, but the PWI can effectively reduce the cumulative error and improve the simulation accuracy and reliability of sensitivity experiments.

Figure 7 shows maps of 48-yr (1958-2005) GHGs-induced precipitation trend from each member of the CONT ensemble, as well as from the "observation," the PWI simulation and the CONT ensemble mean. 
Precipitation trend varies obviously across individual ensemble members, despite the fact that each simulation was conducted using the same model and subjected to the identical radiative forcing. Further, the patterns of precipitation trend can be nearly opposite between individual runs. For example, CONT2 exhibits significantly decreased precipitation over the eastern equatorial Pacific Ocean and the Indian Ocean near Australia, while significantly increased precipitation over the western equatorial Pacific Ocean and western Indian Ocean, while CONT4 shows opposite trends.

The "observation" trend of GHGs-induced precipitation (labeled 'OBS') (Fig. 7, bottom-right panel) shows significant decrease $\left(<0.6 \mathrm{~mm}\right.$ day $^{-1}$ over 48 year) in the eastern equatorial Pacific Ocean, Australia and its nearby waters. While the precipitation significant increase caused by $\mathrm{GHGs}\left(>0.9 \mathrm{~mm}\right.$ day $^{-1}$ over 48 year) in the western equatorial Pacific Ocean and western Indian Ocean. However, CONT4 and CONT5 show opposite trends, and the pattern correlations of each of them with the "observation" are only -0.303 and 0.049 , respectively.

Pattern correlations between each member of the CONT ensemble and the "observation" range from 0.303 to 0.569 , and RMSE range from $0.246 \mathrm{~mm} \mathrm{day}^{-1} 48 \mathrm{yr}^{-1}$ to $0.555 \mathrm{~mm}$ day $^{-1}$ (48 year) ${ }^{-1}$. Pattern correlation between the CONT ensemble mean and the "observation" is 0.509 , and RMSE is $0.206 \mathrm{~mm}$ day $^{-1}$ (48 year) ${ }^{-1}$. While pattern correlation between the PWI simulation and the "observation" is 0721 , and RMSE is $0.139 \mathrm{~mm}$ day $^{-1}$ (48 year) ${ }^{-1}$ (Fig. 7). Moreover, Fig. 8 shows the difference of precipitation trend (1958-2005) caused by GHGs between the PWI simulation and the "observation" is smaller than that between the CONT simulation and the "observation". The difference of precipitation trend between the simulation of each member of the CONT ensemble and the "observation" range from $0.012 \mathrm{~mm}$ day $^{-1}$ $(48 \text { year })^{-1}$ to $0.031 \mathrm{~mm} \mathrm{day}^{-1}$ (48 year) $^{-1}$, and that between the CONT ensemble mean and the "observation" is $0.022 \mathrm{~mm}$ day $^{-1}$ (48 year) ${ }^{-1}$. While the difference of precipitation trend between the PWI simulation and the "observation" is only $0.007 \mathrm{~mm} \mathrm{day}^{-1}$ (48 year) $)^{-1}$.

\section{Conclusions And Discussion}

In the long-term integration, the model systematic errors may accumulate during long-term integration as a result of incomplete physical and numerical representation, which may cause large uncertainty when evaluating climate response to changes in external forcing. To reduce these errors, we present a new PWI method to attribute climate change. The PWI splits the continuous long-term simulation into subintervals of sequential short-term simulations, and the simulation is updated by re-initialization at the end of each subinterval for the experiment.

We first performed a sets of sensitivity experiments based on the "perfect" CESM1.2.0_rl_0.9 with higher rl of 0.9 and original CESM1.2.0 with default rl of 0.8875 to test the hypothesis that the model error, interpreting the long-term trend, keeps the same under different external forcing.

The rl in CESM1.2.0 is lower than that in CESM1.2.0_rl_0.9, which leads to the increase of low-cloud coverage, the decrease of solar shortwave radiation to the Earth surface, and the decrease of surface air 
temperature. Therefore, in the historical simulation, the 2-m temperature by the CONT are lower than the "observation," and the model-"observation" biases are large. The simulation by the PWI is able to reproduce the changing of the "observation." The PWI can effectively reduce the cumulative error and improve the simulation accuracy and reliability. The same results are also obtained in GHG-fixed simulations, but its simulation accuracy is not as good as the historical run, because the state of GHGsfixed simulation by PWI is updated by adding the difference between "observational" and PWI historical runs.

Our PWI simulations present a GHGs-induced global warming trend of $0.688^{\circ} \mathrm{C}$ (48 year) ${ }^{-1}$, which is very close to the "observational" trend of $0.683^{\circ} \mathrm{C}(48 \text { year })^{-1}$. This result confirms our hypothesis of constant model bias under different external forcing and shows that the PWI method can effectively reduce model's cumulative error. The continuous runs, as usually done by the CMIP models, present a much higher GHGs-induced global warming trend of $0.887^{\circ} \mathrm{C}(48 \text { year })^{-1}$, which means that the model overestimates the GHGs's role in global warming trend by $32.3 \%$ compared to our "observations". Further analyses of 48-yr GHGs-induced 2-m temperature trend show that the model bias mainly occur in highlatitude region.

The PWI simulations presents a GHGs-induced global precipitation trend of $0.020 \mathrm{~mm}$ day $^{-1}$ (48 year) ${ }^{-1}$, which means that the PWI overestimates the GHGs role in global precipitation trend by $53.8 \%$ compared to the "observation" which is $0.013 \mathrm{~mm}^{-1 a y}{ }^{-1}$ ( 48 year) ${ }^{-1}$. While that the CONT ensemble mean of $0.035 \mathrm{~mm} \mathrm{day}^{-1}$ (48 year) ${ }^{-1}$ overestimates the GHGs role in global precipitation trend by $169.2 \%$ compared to the "observation". Further analyses maps of 48-yr GHGs-induced precipitation trend, the results show that the error of PWI simulation is less than that of CONT simulation. The accuracy of precipitation simulated by the PWI is not as good as that of 2-m temperature, the main reason may be that the specific humidity is not updated.

The above results show that the ensemble mean of the CONT still cannot eliminate possible systematic errors, while the PWI can effectively reduce the cumulative errors and improve the simulation accuracy and reliability of the sensitivity experiments. The PWI has provided good results in the test and application of complex climate model of the CESM. The realistic observation or reanalysis data instead of our mimicking "observation" can be used to the attribution analysis in the future works.

\section{Declarations}

\section{Conflict of interest:}

The authors declare that they have no conflict of interest.

\section{Acknowledgments:}


We are very grateful to Prof. Qiu Chongjian for proposing the piecewise integration method and giving guidance to this paper. This work was funded by the National Key R\&D Program of China (2016YFA0602703). This work was jointly supported by the National Natural Science Foundation of China (Grant Nos. 41775092 and 41975086), the Fundamental Research Funds for the Central Universities (Grant No. 20lgzd06).

\section{References}

1. Andreao W, Maciel F, Pedruzzi R, Pinto JA, Albuquerque T INVESTIGATION OF RUN SEGMENTS IN WRF FOR A DRY MONTH IN MESOSCALE. In: Air Pollution Conference Brazil 4th CMAS South America, 2019.

2. Bennett AF, Leslie LM (1981) Statistical Correction of the Australian Region primitive Equation Model. Monthly Weather Review 109:453-462

3. Bony S et al. (2015) Clouds, circulation and climate sensitivity. Nature Geoscience 8:261-268

4. Cesana G, Waliser DEJGRL (2016) Characterizing and understanding systematic biases in the vertical structure of clouds in CMIP5/CFMIP2 models. 43:10,538-510,546

5. Chai J, Liu F, Xing C, Wang B, Gao C, Liu J, Chen D (2020) A robust equatorial Pacific westerly response to tropical volcanism in multiple models. Climate Dynamics 55:3413-3429

6. Cornes RC, van der Schrier G, van den Besselaar EJM, Jones PD (2018) An Ensemble Version of the E-OBS Temperature and Precipitation Data Sets. Journal of Geophysical Research: Atmospheres 123:9391-9409

7. Cowtan K, Way RG (2014) Coverage bias in the HadCRUT4 temperature series and its impact on recent temperature trends. Quarterly Journal of the Royal Meteorological Society 140:1935-1944

8. Frei C, Isotta FA (2019) Ensemble Spatial Precipitation Analysis From Rain Gauge Data: Methodology and Application in the European Alps. Journal of Geophysical Research: Atmospheres 124:57575778

9. Gan R, Yang Y, Ma Y (2019) Modelling the impacts of the Pacific Ocean sea surface temperature anomalies on a drought event in southwestern China with a piecewise-integration method. International Journal of Climatology 39:799-813

10. Gupta AS, Jourdain NC, Brown JN, Monselesan D (2013) Climate Drift in the CMIP5 Models*. Journal of Climate 26:8597-8615

11. Hawkins E, Sutton R (2009) The Potential to Narrow Uncertainty in Regional Climate Predictions. Bulletin of the American Meteorological Society 90:1095-1108

12. Held IM, Soden BJJJoC (2006) Robust Responses of the Hydrological Cycle to Global Warming. Journal of Climate 19:5686-5699

13. Hurrell JW et al. (2013) The Community Earth System Model: A Framework for Collaborative Research. Bulletin of the American Meteorological Society 94:1339-1360 
14. Ji Y, Vernekar AD (2010) Simulation of the Asian Summer Monsoons of 1987 and 1988 with a Regional Model Nested in a Global GCM. Journal of Climate 10:1965-1979

15. Jones GS, Stott PA, Christidis N (2013) Attribution of observed historical nearsurface temperature variations to anthropogenic and natural causes using CMIP5 simulations. Journal of Geophysical Research Atmospheres 118:4001-4024

16. Kalnay E (2002) Atmospheric modeling, data assimilation and predictability: Post-processing of numerical model output to obtain station weather forecasts.

17. Kennedy JJ, Rayner NA, Atkinson CP, Killick RE (2019) An Ensemble Data Set of Sea Surface Temperature Change From 1850: The Met Office Hadley Centre HadSST.4.0.0.0 Data Set. Journal of Geophysical Research: Atmospheres 124:7719-7763

18. Knutti R, Furrer R, Tebaldi C, Cermak J, Meehl GA (2010) Challenges in Combining Projections from Multiple Climate Models. Journal of Climate 23:2739-2758

19. Koster RD, Walker GK, Mahanama SPP, Reichle RH (2014) Soil Moisture Initialization Error and Subgrid Variability of Precipitation in Seasonal Streamflow Forecasting. Journal of Hydrometeorology 15:69-88

20. Lo JC-F, Yang Z-L, Pielke RA (2008) Assessment of three dynamical climate downscaling methods using the Weather Research and Forecasting (WRF) model. Journal of Geophysical Research 113

21. Lorenc AC (2015) DATA ASSIMILATION AND PREDICTABILITY | Data Assimilation. Encyclopedia of Atmospheric Sciences:237-240

22. Lucas-Picher P, Boberg F, Christensen JH, Berg P (2013) Dynamical Downscaling with Reinitializations: A Method to Generate Finescale Climate Datasets Suitable for Impact Studies. Journal of Hydrometeorology 14:1159-1174

23. Matthew OJ, Abiye OE, Sunmonu LA, Ayoola MA, Oluyede OT (2017) uncertainties-in-the-estimationof-global-observational-network-datasetsof-precipitation-over-west-africa-2332-2594-1000210.

24. Morice CP, Kennedy JJ, Rayner NA, Jones PD (2012) Quantifying uncertainties in global and regional temperature change using an ensemble of observational estimates: The HadCRUT4 data set. Journal of Geophysical Research Atmospheres 117

25. Nam C, Bony S, Dufresne JL, Chepfer H (2012) The 'too few, too bright' tropical low-cloud problem in CMIP5 models. Geophysical Research Letters 39:21801

26. Neale RB et al. (2010) Description of the NCAR Community Atmosphere Model (CAM 5.0), Tech. Note NCAR/TN-486+STR, Natl. Cent. for Atmos. Land Model ncar Technote Ncar tn-486+str

27. Pan Z, Takle E, Gutowski W, Turner R (1999) Long Simulation of Regional Climate as a Sequence of Short Segments. Monthly Weather Review 127:308

28. Parry ML, Canziani OF, Palutikof JP, Van D, Hanson CE (2007) IPCC Fourth Assessment Report: Climate Change 2007 (AR4).

29. Qian JH, Seth A, Zebiak SJMWR (2003) Reinitialized versus Continuous Simulations for Regional Climate Downscaling. 131:2857 
30. Sagita N, Fatkhuroyan F (2016) Using 3D-Var Data Assimilation for Improving the Accuracy of Initial Condition of Weather Research and Forecasting (WRF) Model in Java Region (Case Study : 23 January 2015).

31. Shao A, Qiu C, Niu G-Y (2015) A Piecewise Modeling Approach for Climate Sensitivity Studies: Tests with a shallow-water model. Journal of Meteorological Research

32. Stevens B, Bony S (2013) What Are Climate Models Missing? Science 340:1053-1054

33. Tebaldi C, Knutti R (2007) The use of the multi-model ensemble in probabilistic climate projections. Philos Trans A Math Phys Eng 365:2053-2075

34. Wang D, You W, Zang Z, Pan X, He H, Liang Y (2020) A three-dimensional variational data assimilation system for a size-resolved aerosol model: Implementation and application for particulate matter and gaseous pollutant forecasts across China. Science China Earth Sciences 63:1366-1380

35. Wang X (2017) Experimental study on the application of piecewise integration method to assess the impact of greenhouse gas emissions on past climate chang. master, Lanzhou University

36. Wu H, Su D, Fan X Impacts of Doppler Radar Data Assimilation on Precipitation Forecast of a Severe Convective Process in Hainan, China. In: 2019 International Conference on Meteorology Observations (ICMO), 2020.

37. Zhang Z, Qiu C, Wang C (2008) A piecewise-integration method for simulating the influence of external forcing on climate. Progress in Natural Science 18:1239-1247

\section{Figures}




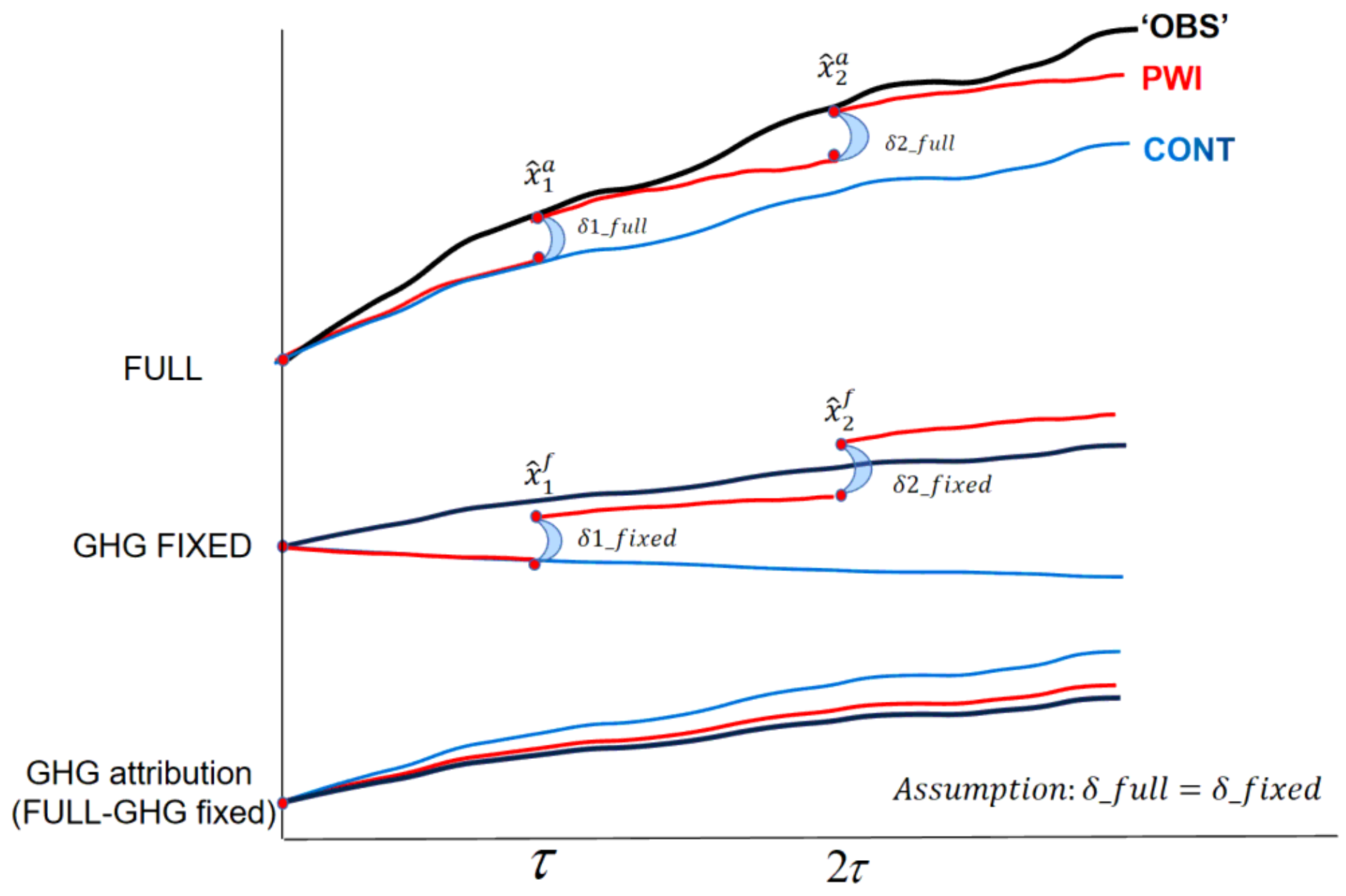

Figure 1

Schematic diagram of PWI experiments. At each $\tau=1$ day step, the PWI (red lines) historical and GHG-fixed runs in CESM1.2.0 are corrected by the difference between the PWI and "observational" (black line) historical runs, based on the hypothesis of constant model error under different external forcing. The "observational" historical and GHG-fixed runs are integrated continuously by using CESM1.2.0_rl_0.9. The GHG attribution to global warming can be represented by the difference between historical and GHG-fixed experiments. Six continuous runs are performed for both historical and GHG-fixed runs by using Model1.2.0. 

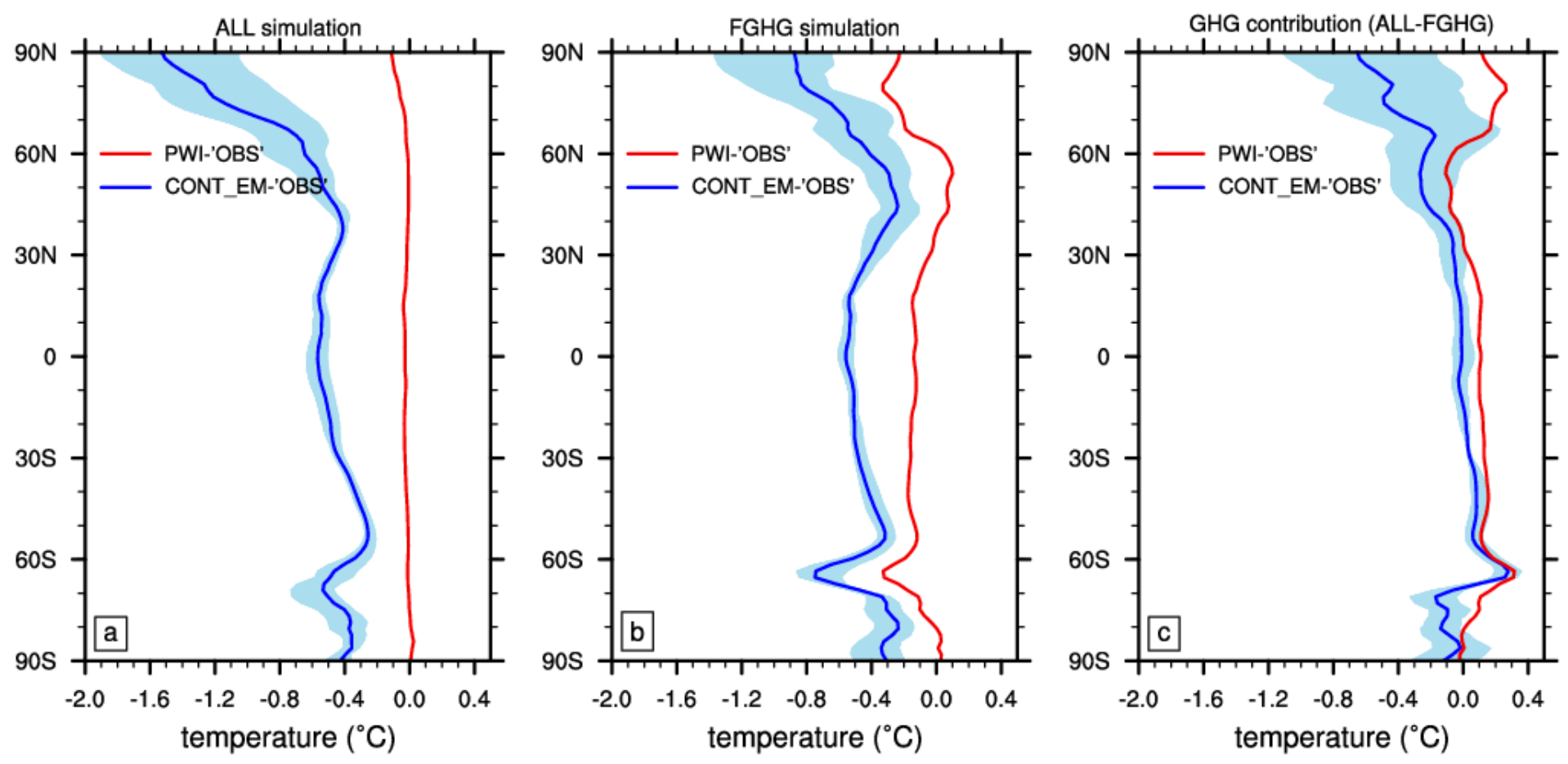

Figure 2

The variation with the latitude of globally averaged 2-m temperature difference during 1958-2005 between the PWI simulation and the "observation" (red line), and that between the CONT ensemble mean and the "observation" (blue line) for (a) the historical simulation, (b) the GHGs-fixed simulation, and (c) their difference. 

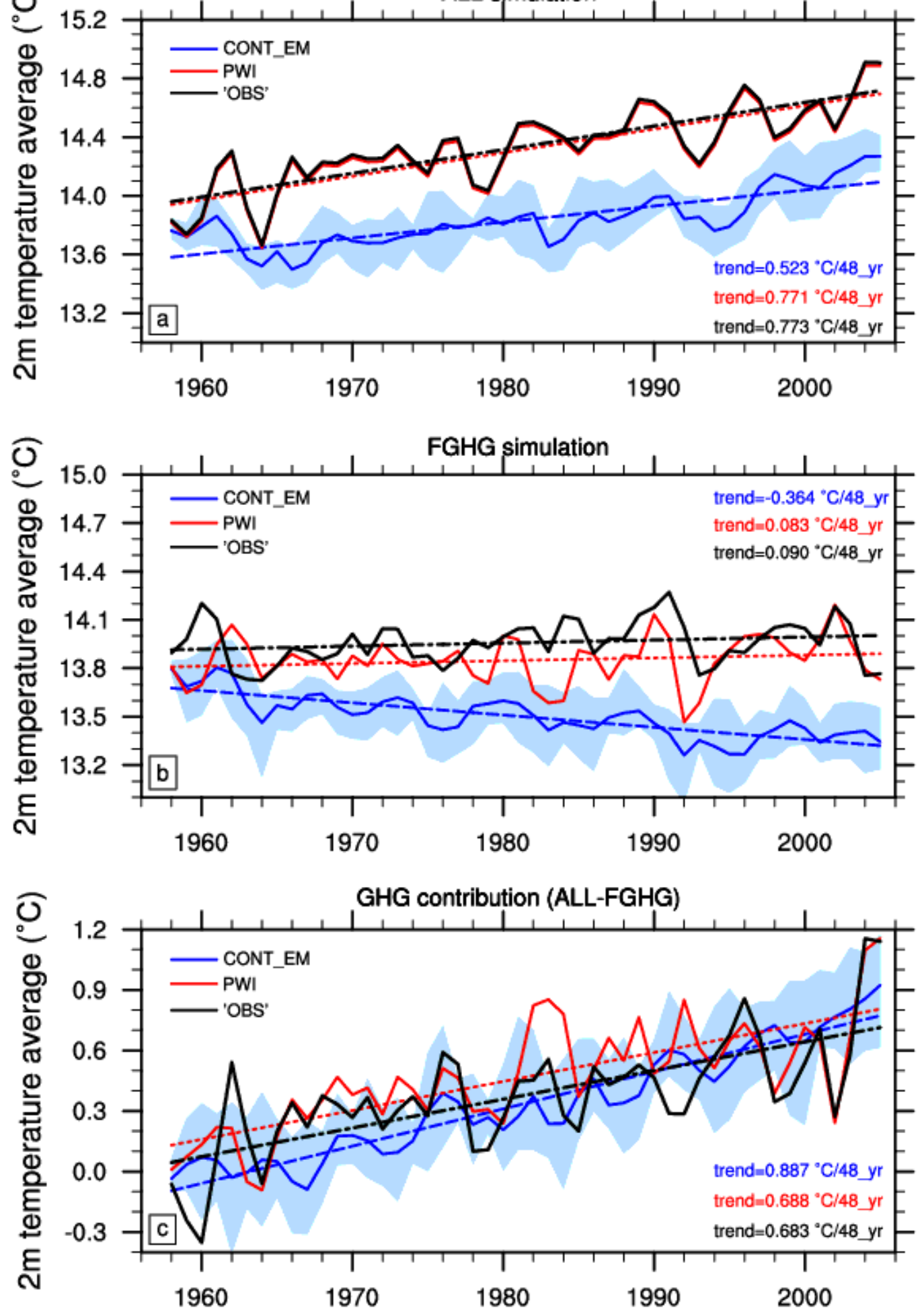

\section{Figure 3}

Temporal variation of globally averaged 2-m temperature (solid line) and its linear regression (dotted line) during 1958-2005 with respect to "observation" (black), PWI (red), and CONT ensemble mean (blue) in (a) historical simulation, (b) GHGs-fixed simulation, and (c) their difference, denoting the GHG effect. Blude shading denotes the range of six ensembles of the continuous runs. The linear trend of globally averaged temperature is also presented. 

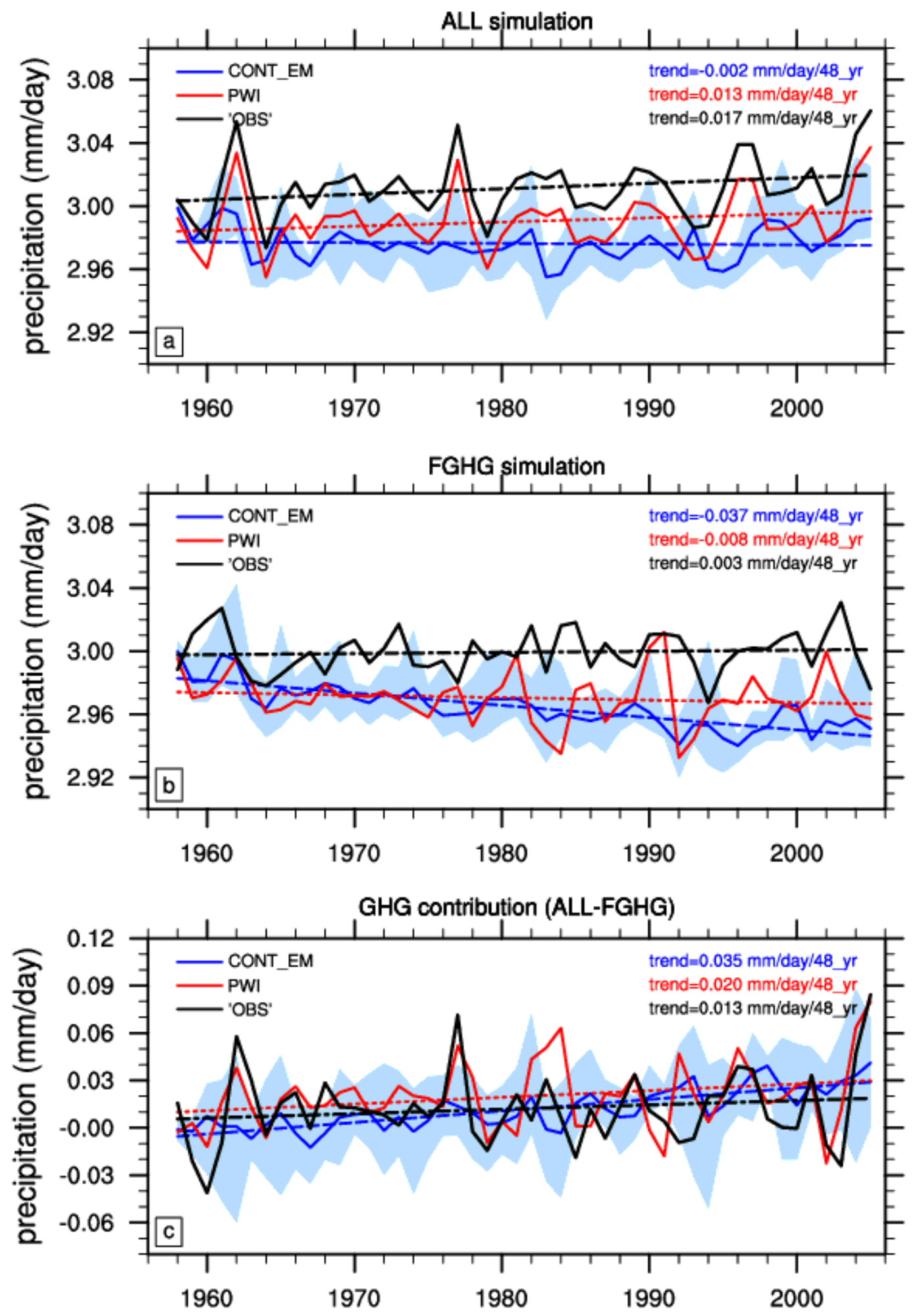

Figure 4

Same as in Fig. 3 except for globally averaged precipitation. 


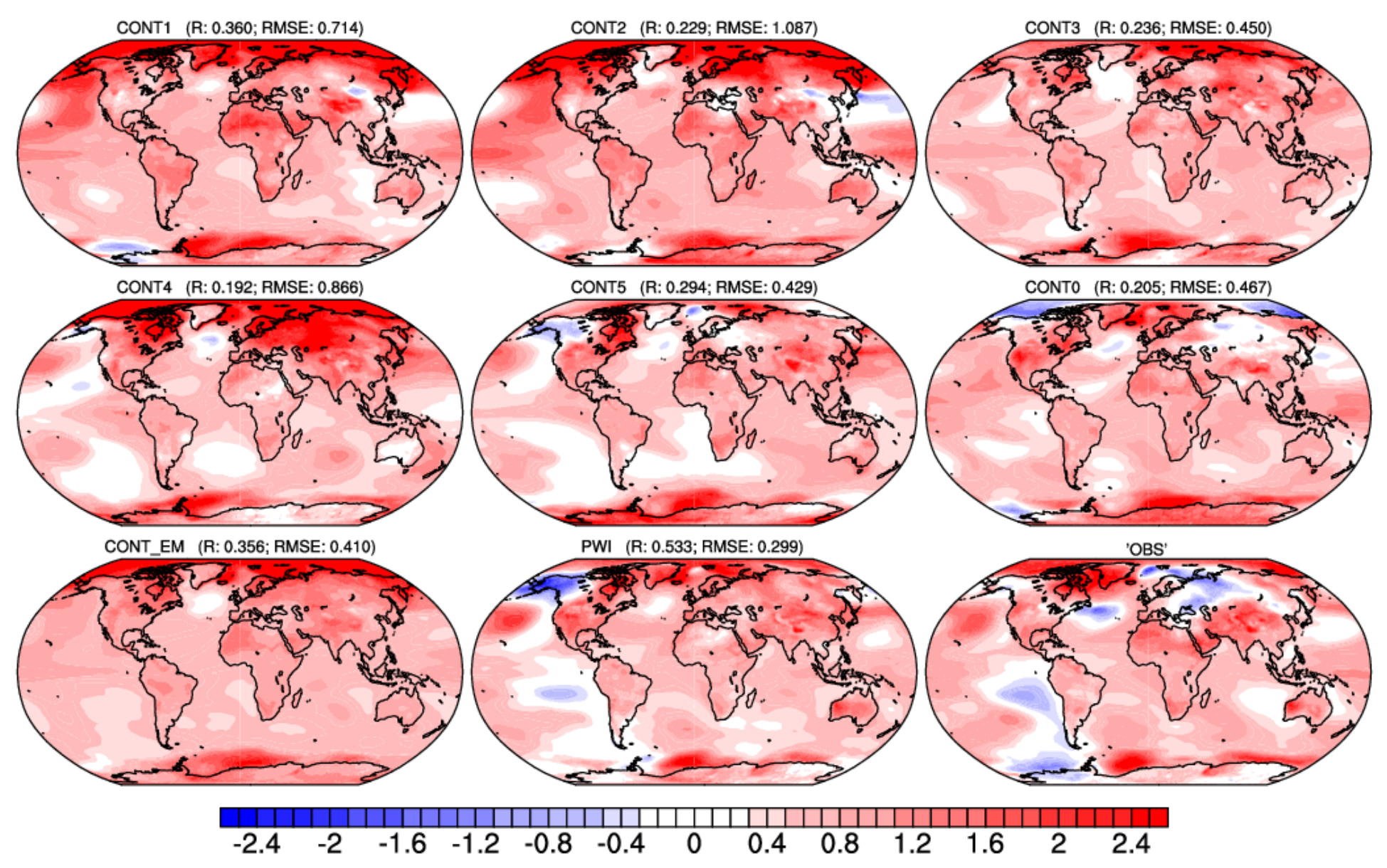

Figure 5

Two-meter temperature $\left({ }^{\circ} \mathrm{C}(48 \mathrm{yr})-1\right)$ trends (1958-2005) caused by GHGs for each member of the CONT ensemble (CONTO: unperturbed initial field; CONT1-CONT5: perturbed initial field), the CONT ensemble mean (labeled EM), PWI (labeled PWI), and "observation" (labeled 'OBS'). Note: The designations employed and the presentation of the material on this map do not imply the expression of any opinion whatsoever on the part of Research Square concerning the legal status of any country, territory, city or area or of its authorities, or concerning the delimitation of its frontiers or boundaries. This map has been provided by the authors. 


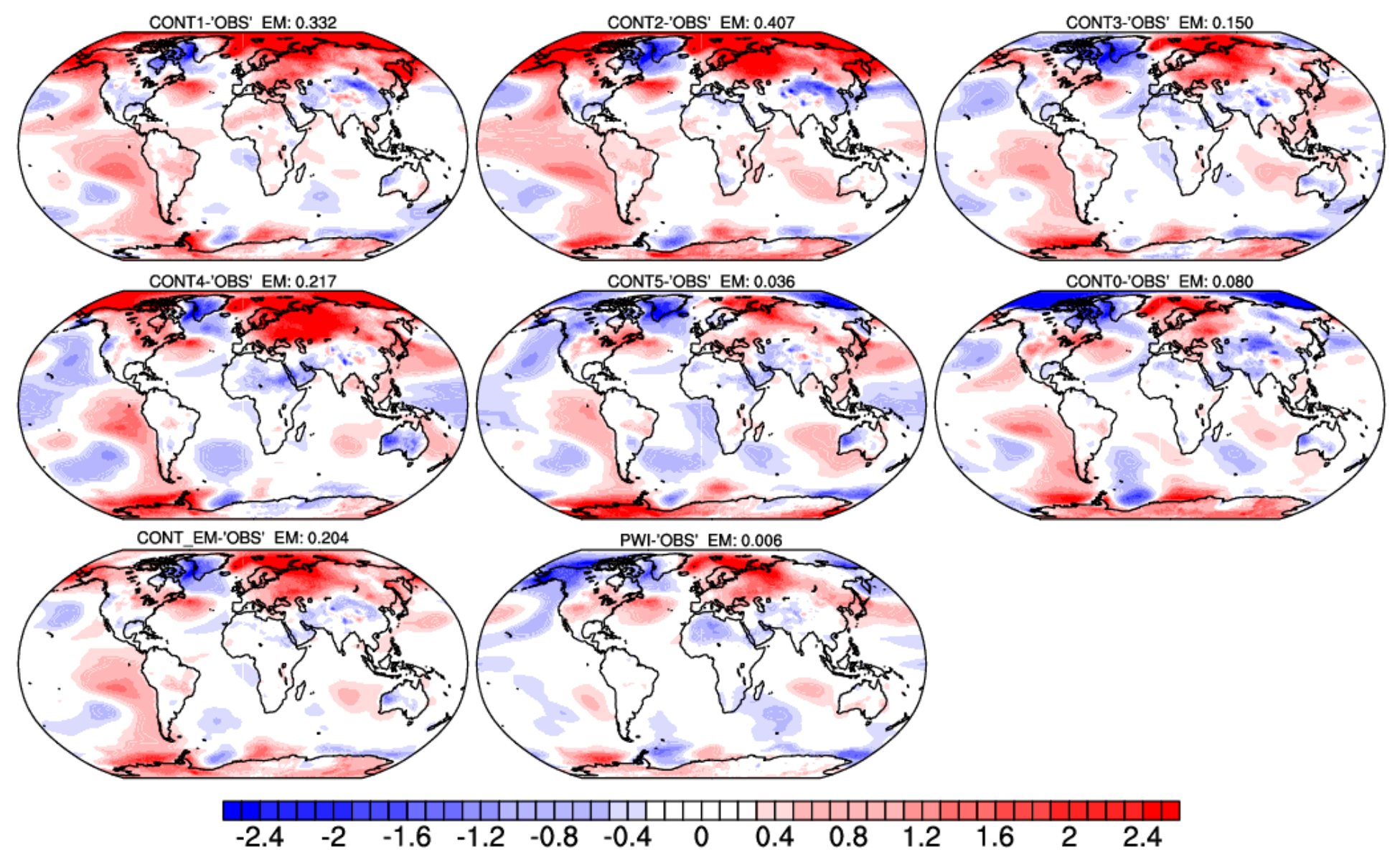

Figure 6

Difference of 2-m temperature ( ${ }^{\circ} \mathrm{C}$ (48yr)-1) trends (1958-2005) caused by GHGs between each member of CONT ensemble and "observation" (CONT1-'OBS', CONT2-'OBS', CONT3-'OBS', CONT4'-OBS', CONTO'OBS'), CONT ensemble-mean and "observation" (labeled CONT_EM-'OBS'), and PWI and "observation" (labeled PWI'OBS'). Note: The designations employed and the presentation of the material on this map do not imply the expression of any opinion whatsoever on the part of Research Square concerning the legal status of any country, territory, city or area or of its authorities, or concerning the delimitation of its frontiers or boundaries. This map has been provided by the authors. 


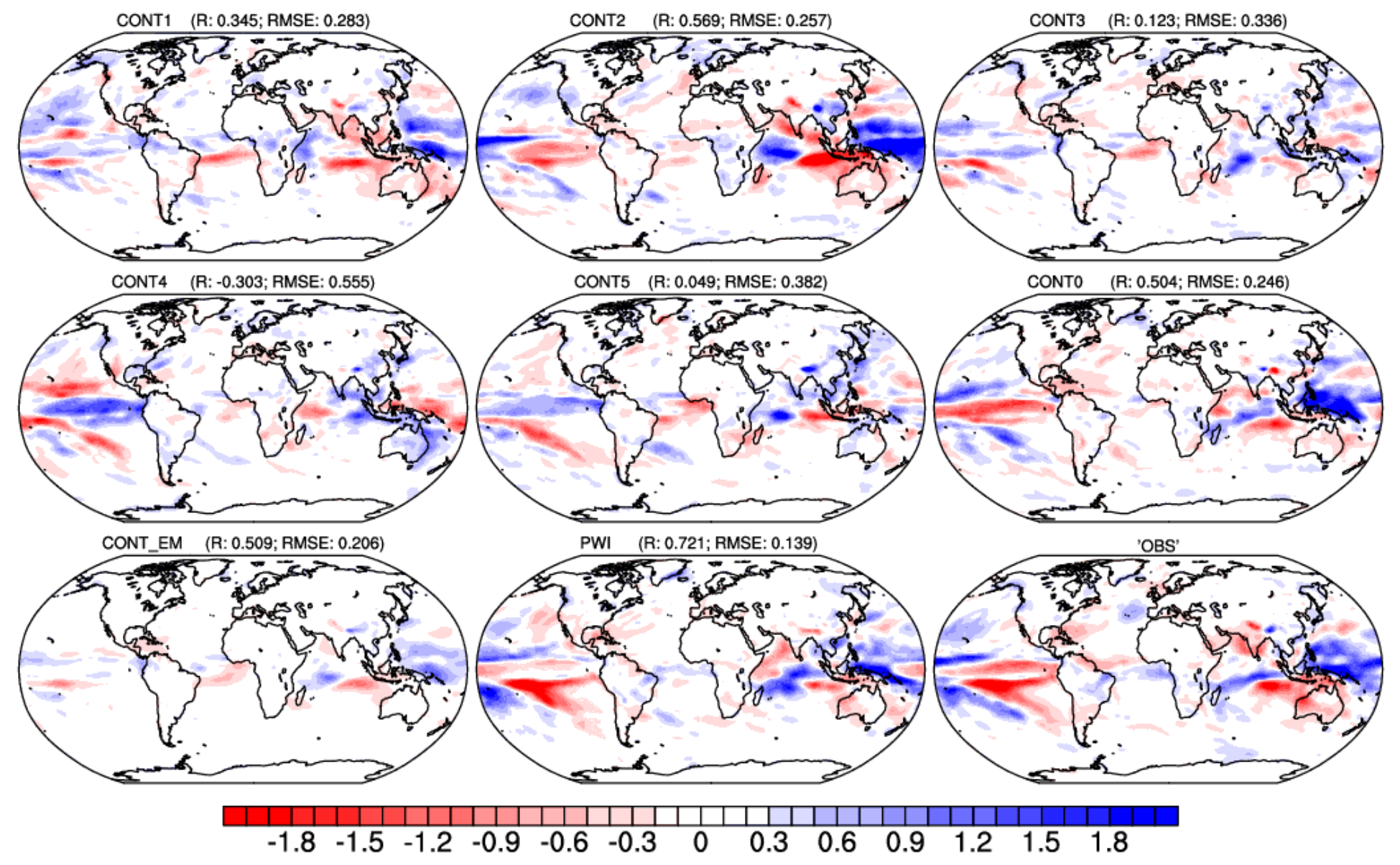

Figure 7

Same as in Fig. 5 except for precipitation (mm day-1 (48yr)-1) trends. Note: The designations employed and the presentation of the material on this map do not imply the expression of any opinion whatsoever on the part of Research Square concerning the legal status of any country, territory, city or area or of its authorities, or concerning the delimitation of its frontiers or boundaries. This map has been provided by the authors. 


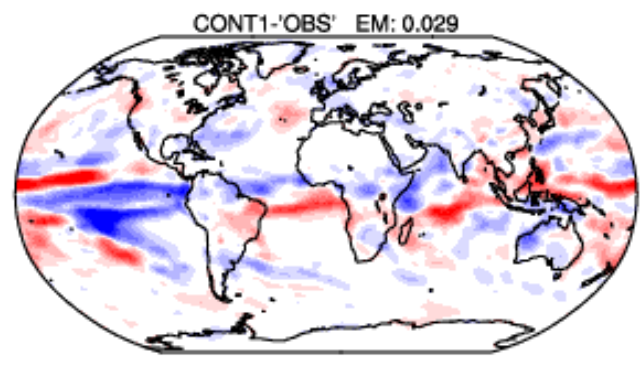

CONT4-'OBS' EM: 0.031

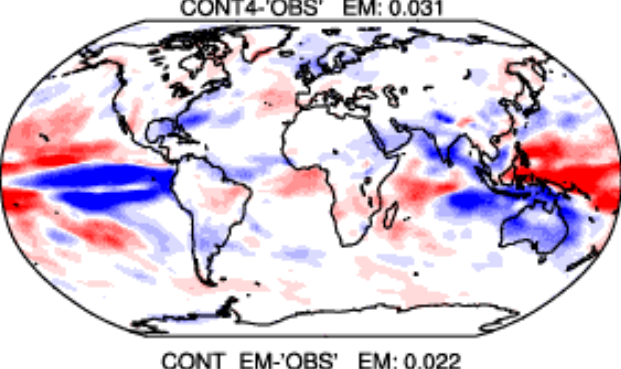

CONT_EM-'OBS' EM: 0.022
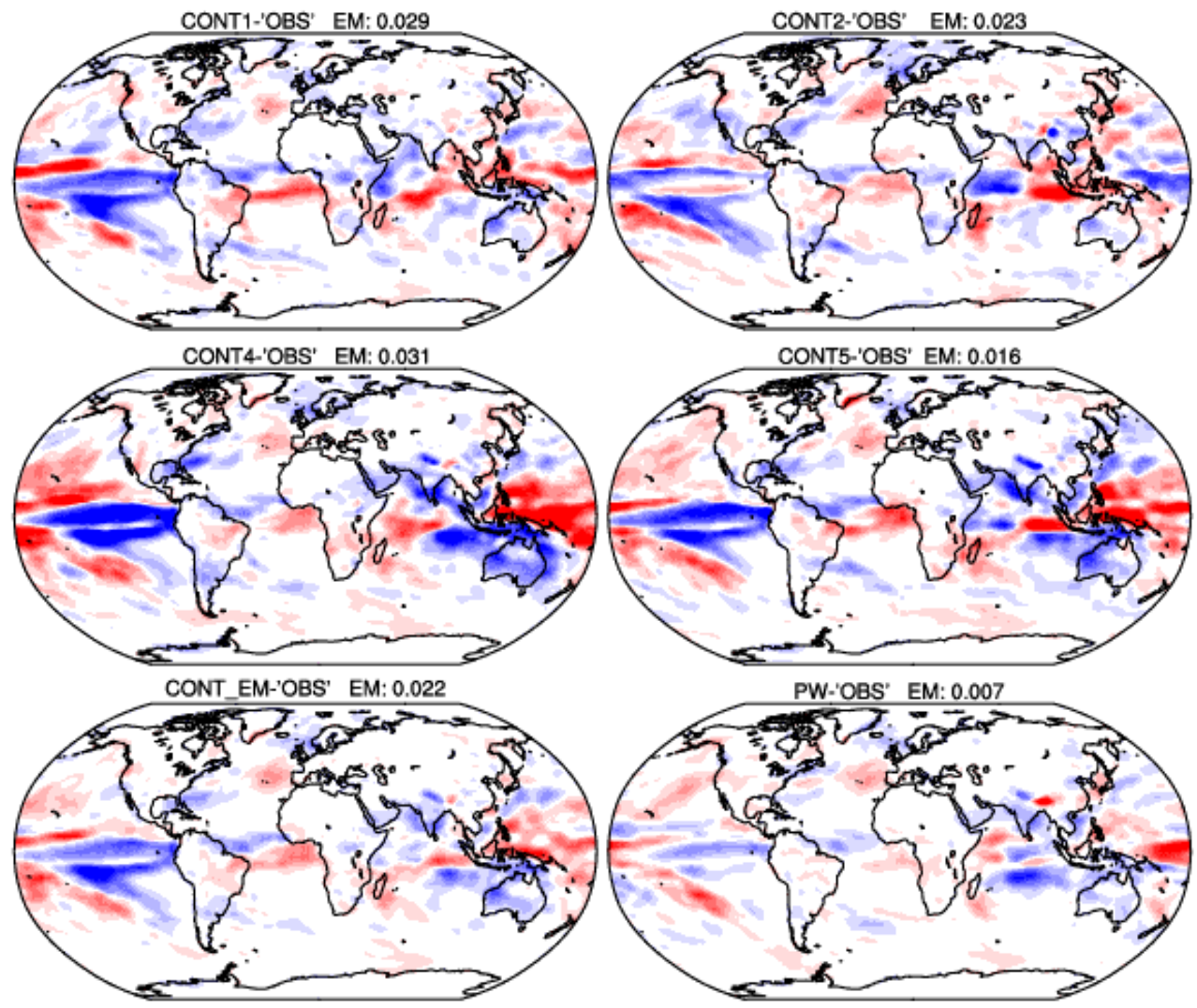

CONT5-'OBS' EM: 0.016

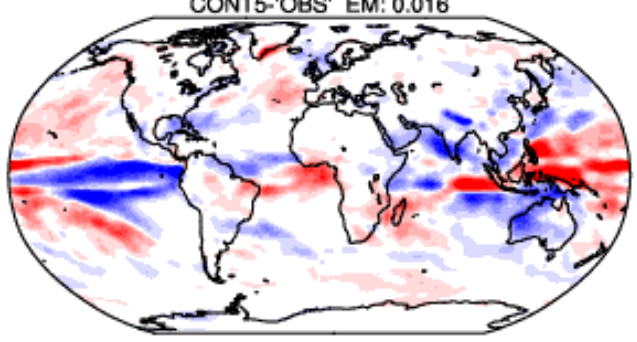

PW-'OBS' EM: 0.007
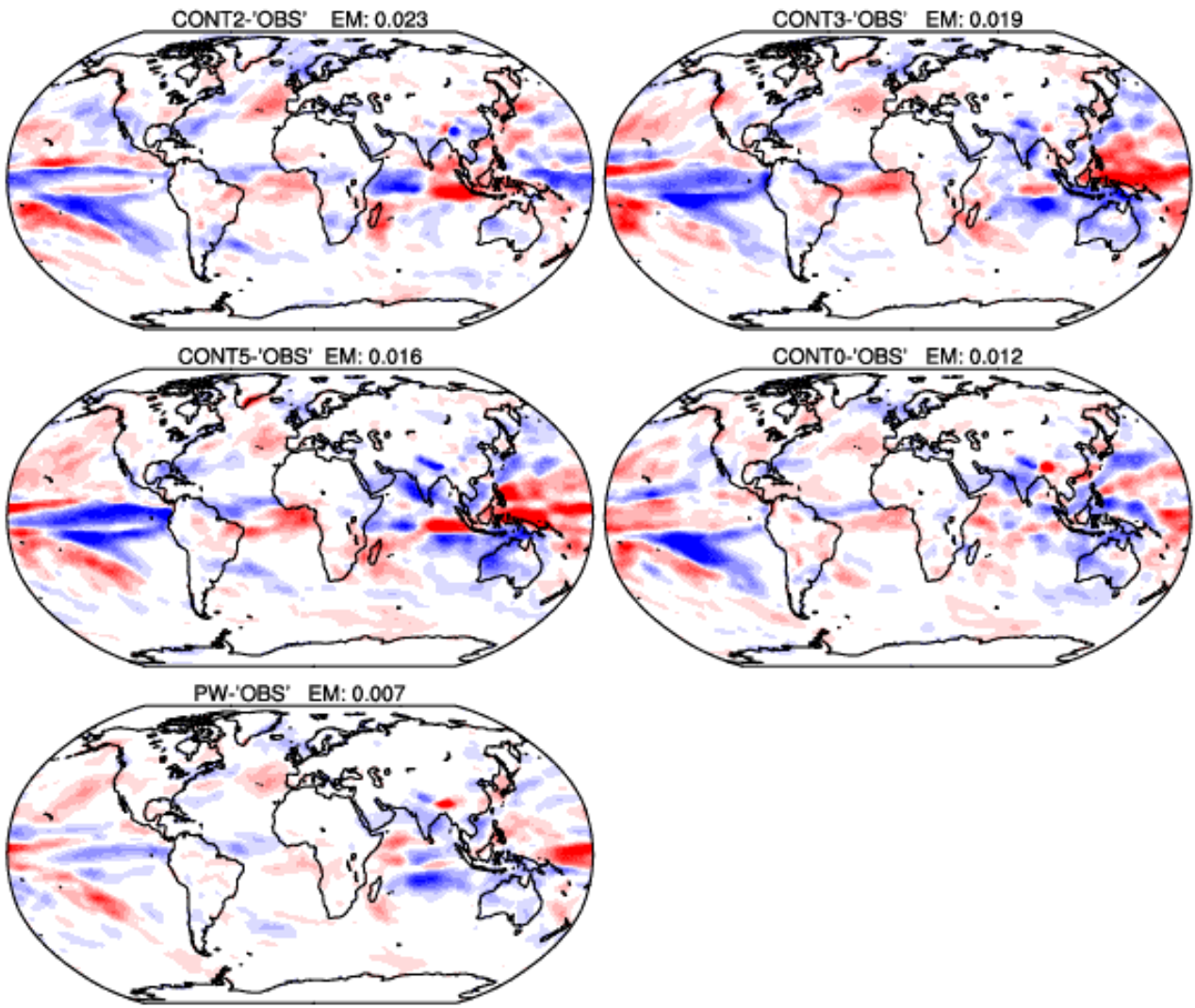

CONTO-'OBS' EM: 0.012

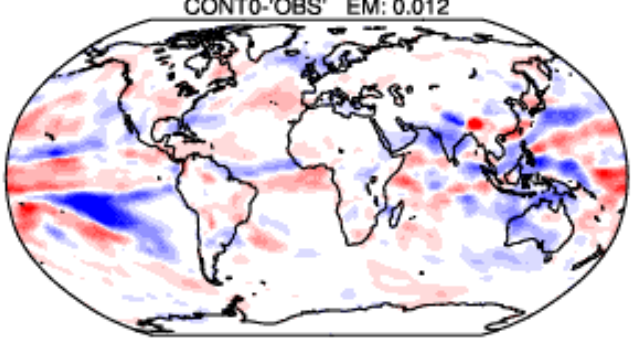

$\begin{array}{lllllllllllll}-1.8 & -1.5 & -1.2 & -0.9 & -0.6 & -0.3 & 0 & 0.3 & 0.6 & 0.9 & 1.2 & 1.5 & 1.8\end{array}$

Figure 8

Same as in Fig. 6 except for difference of precipitation (mm day-1 (48yr)-1). Note: The designations employed and the presentation of the material on this map do not imply the expression of any opinion whatsoever on the part of Research Square concerning the legal status of any country, territory, city or area or of its authorities, or concerning the delimitation of its frontiers or boundaries. This map has been provided by the authors. 